\title{
A New Molecular Detection System for Canine Distemper Virus Based on a Double-Check Strategy
}

\author{
Sabrina Halecker ${ }^{1}{ }^{+}$, Sabine Bock ${ }^{2}$, Martin Beer ${ }^{1}$ and Bernd Hoffmann ${ }^{1, *(D)}$ \\ 1 Institute of Diagnostic Virology, Friedrich-Loeffler-Institut, Federal Research Institute for Animal Health \\ Südufer 10, 17493 Greifswald-Insel Riems, Germany; Sabrina.Halecker@fu-berlin.de (S.H.); \\ martin.beer@fli.de (M.B.) \\ 2 Landeslabor Berlin-Brandenburg, Gerhard-Neumann-Str. 2, 15236 Frankfurt (Oder), Germany; \\ Sabine.Bock@Landeslabor-bbb.de \\ * Correspondence: Bernd.Hoffmann@fli.de; Tel.: +49-3835-171-506 \\ + Current Adress: Institute of Virology, Freie Universität Berlin, Robert von Ostertag-Straße 7-13, \\ 14163 Berlin, Germany.
}

\begin{abstract}
Due to changing distemper issues worldwide and to inadequate results of an interlaboratory study in Germany, it seems sensible to adapt and optimize the diagnostic methods for the detection of the canine distemper virus (CDV) to the new genetic diversity of virus strains. The goal of the project was the development, establishment and validation of two independent one-step reverse transcriptase quantitative polymerase chain reaction (RT-qPCR) methods for the safe detection of CDV in domestic and wild animals. For this purpose, an existing CDV-RT-qPCR was decisively adapted and, in addition, a completely new system was developed. Both CDV-RT-qPCR systems are characterized by a very high, comparable analytical and diagnostic sensitivity and specificity and can be mutually combined with inhibition or extraction controls. The reduction in the master mix used allows for the parallel implementation of both CDV-RT-qPCR systems without significant cost increases. For validation of the new CDV-RT-qPCR duplex assays, a panel comprising 378 samples derived from Germany, several European countries and one African country were tested. A sensitivity of $98.9 \%$ and a specificity of $100 \%$ were computed for the new assays, thus being a reliable molecular diagnostic tool for the detection of CDV in domestic and wild animals.
\end{abstract}

Keywords: canine distemper; Canine morbillivirus; diagnostic; RT-qPCR; domestic animal; wildlife population; double-check strategy

Academic Editor: Subir Sarker

Received: 6 July 2021

Accepted: 11 August 2021

Published: 18 August 2021

Publisher's Note: MDPI stays neutral with regard to jurisdictional claims in published maps and institutional affiliations.

\section{Introduction}

The canine distemper virus (CDV) causes a severe, highly contagious infectious disease, affecting mainly carnivores [1-3]. CDV (taxonomic name: Canine morbillivirus) was first mentioned in 1760 and belongs to the genus Morbillivirus in the family Paramyxoviridae of the order Mononegavirales [4,5]. The genome of CDV encodes for eight proteins designated as nucleocapsid $(\mathrm{N})$, phospho- $(\mathrm{P})$, matrix $(\mathrm{M})$, fusion $(\mathrm{F})$, hemagglutinin $(\mathrm{H})$, large polymerase (L) (structural proteins), and $\mathrm{C}$ and $\mathrm{V}$ proteins (nonstructural proteins) [6]. Serologically, the virus is classified into one serotype and distinct lineages that are genetically determined by sequence differences in the $H$ gene [7]. According to their geographical distribution, the CDV lineages are clustered currently as America 1 to 4 , South-America 1 to 3, Africa 1 to 2, Asia 1 to 2, Europe, European Wildlife, Arctic-like and Rockborn-like. In Europe, CDV isolates of the lineages Europe, European Wildlife and Arctic-like are predominant $[3,6,8,9]$.

In recent years, an increase in the incidence of distemper disease in the global dog population as well as massive outbreaks in global wildlife were recorded [3,10-12]. Additionally, in European wildlife, outbreaks of distemper infections were reported progressively [13-19]. Overall, the vaccine fatigue of animal owners and the failure of established 
vaccines in connection with new virus variants are considered the cause of the rise in distemper cases $[2,10,20-23]$. A spillover of CDV from the dog to wild population and vice versa is suspected and poses a serious threat to endangered species [12,18,23-26].

Concerns about the increasing number of cases of canine distemper virus indicate the importance of targeted surveillance of CDV in susceptible species [17] and the need to reconsider established diagnostic methods for the detection of CDV. An inter-laboratory proficiency test conducted in Germany revealed standout deficiencies in the detection of certain CDV sequences detected by CDV reverse transcriptase quantitative polymerase chain reaction (RT-qPCR) assays commonly used. Consequently, a sequence alignment of CDV sequences from an international database (National Center for Biotechnology Information, NCBI) with the primer-probe sequences of established RT-qPCR assays was carried out. The results indicated the drawbacks of the RT-qPCR systems currently in use; thus, we strived for an adaption to the new virus variants. Commonly used RT-qPCR systems for the detection of CDV with relevance to this study are based on the primerprobe mixes described by Elia and co-workers and by Scagliarini and co-workers [27,28]. The ELIA assay is located on the $N$ gene, and the analytical sensitivity was determined as $10^{2}$ genome equivalent $(\mathrm{GE}) / \mu \mathrm{L}$, while the primer-probe mix of the Scagliarini assay targeting the P protein demonstrated a limit of detection (LOD) of $10^{1} \mathrm{GE} / \mu \mathrm{L}[27,28]$.

In this study, an established CDV-RT-qPCR assay designed by Scagliarini and coworkers was decisively adapted and a new CDV-RT-qPCR assay was designed based on the latest available CDV sequence information. To ensure a safe and sensitive detection of broad-range CDV sequences, the new diagnostic approach is targeted on a double-check strategy as described previously for other pathogens [29,30]. Both CDV-RT-qPCR assays were equipped with internal controls (IC) and validated with a comprehensive validation panel comprising 378 samples, where 180 specimens tested negative and 198 positive for CDV.

\section{Materials and Methods}

\subsection{Samples}

For this study, a total of 378 animal samples were available from routine diagnostics including 198 CDV-positive (52.4\%) and 180 negative samples (47.6\%) that were predetermined by an established, routinely used CDV-specific RT-qPCR assay described by Elia and co-workers [27]. The majority of sampling was carried out on domestic and wild animals in the German federal states Hesse $(n=139)$, Brandenburg $(n=2)$, Berlin $(n=1)$, Lower Saxony $(\mathrm{n}=1)$, Saxony Anhalt $(\mathrm{n}=1)$ and Thuringia $(\mathrm{n}=1)$. The panel is also comprised of specimens derived from Austrian $(n=8)$, Italian $(n=1)$, Spanish $(n=1)$, Romanian $(\mathrm{n}=1)$, Ukrainian $(\mathrm{n}=1)$ and African $(\mathrm{n}=1)$ animals, allowing for the inclusion of a wider geographical distribution. Among the animal specimens, $47 \%$ were collected from foxes $(n=179)$ and $29 \%$ were collected from racoons $(n=111)$, while further sample material is represented by martens $(n=23)$, dogs $(n=18)$, racoon dogs $(n=8)$, wolves $(n=8)$, badgers $(n=6)$, minks $(n=6)$, polar fox $(n=1)$, otter $(n=1)$, red panda $(n=1)$ and without specification $(n=11)$. More than one tissue sample was available from some animals.

Additionally, a $\log _{10}$ dilution series $\left(10^{-1}\right.$ to $\left.10^{-8}\right)$ of the CDV strain "Onderstepoort" (sample ident number: $\mathrm{BH}$ 04/18-2) was used and a small panel of phocine distemper virus (PDV)-positive samples $(n=4)$ was also tested.

\section{2. $C D V-R T-q P C R$ Assays}

To improve the reliability of canine distemper diagnosis, two CDV-RT-qPCRs were designed for simultaneous application. According to the NCBI database, an existing RTqPCR assay previously published by Scagliarini and co-workers [28] and targeting the $P$ gene was decisively adapted to the latest available CDV sequence information. A second, completely new RT-qPCR was selected from an initial set of 12 varying primer-probe combinations (CDV-Mix 4 to CDV-Mix 15) that were located on heterogeneous genetic locations ( $N, P$ and $L$ gene) within the CDV genome. The primers and TaqMan-probes were 
designed based on an alignment of 2075 CDV sequence information available from the NCBI database.

To further enhance the security of the new detection systems, both CDV-RT-qPCR assays were carried out in parallel with an optimized total reaction volume of $12.5 \mu \mathrm{L}$ per approach and were additionally equipped with two different IC systems (double-check strategy). In this study, the adapted assay by Scagliarini and co-workers, hereinafter designated as CDV-Mix 3, was combined with an IC based on heterologous RNA (EGFPMix 2-HEX) [31] while the newly established RT-qPCR assay was used in combination with an endogenous IC (B-Actin-Mix 2-HEX) [32] (Table 1).

Table 1. Sequences of finally used primers and probes.

\begin{tabular}{|c|c|c|c|c|c|}
\hline PCR Assay & Primer/Probe & Sequence $5^{\prime}-3^{\prime}$ & $\begin{array}{l}\text { Amplicon } \\
\text { Size (bp) }\end{array}$ & Location & Reference \\
\hline ELIA-Mix & $\begin{array}{l}\text { CDV-F } \\
\text { CDV-R } \\
\text { CDV-Pb }\end{array}$ & $\begin{array}{c}\text { AGC TAG TTT CAT CTT AAC TAT CAA ATT } \\
\text { TTA ACT CTC CAG AAA ACT CAT GC } \\
\text { FAM-ACC CAA GAG CCG GAT ACA TAG TTT } \\
\text { CAA TGC-TAMRA }\end{array}$ & 87 & Ngene & Elia et al., 2006 [27] \\
\hline CDV-Mix 3 & $\begin{array}{l}\text { CDV4.1-F } \\
\text { CDV3-R } \\
\text { CD3.1-FAMas }\end{array}$ & $\begin{array}{c}\text { CTG TCR GTA ATC GAG RAT TCG A } \\
\text { GCC GAA AGA ATA TCC CCA GTT AG } \\
\text { FAM-ATC TTC GCC AGA RTC YTC AGT } \\
\text { GCT-BHQ1 }\end{array}$ & 116 & P gene & $\begin{array}{l}\text { Scagliarini et al., } 2007 \\
\text { [28], modified }\end{array}$ \\
\hline CDV-Mix 7 & $\begin{array}{l}\text { CDV-1808-F } \\
\text { CDV-1903-R } \\
\text { CDV-1842-FAM }\end{array}$ & $\begin{array}{c}\text { AGG ARC AGG CCT AYC ATG TCA } \\
\text { TRC TGC TGA CCT CTT GAA TCT C } \\
\text { FAM-ATG CCT CAA ARC CCT CAG AGA GAA } \\
\text { TCC-BHQ1 }\end{array}$ & 96 & Pgene & in this study \\
\hline EGFP-Mix 2-HEX & $\begin{array}{l}\text { EGFP-1-F } \\
\text { EGFP-10-R } \\
\text { EGFP-HEX }\end{array}$ & $\begin{array}{c}\text { GAC CAC TAC CAG CAG AAC AC } \\
\text { CTT GTA CAG CTC GTC CAT GC } \\
\text { HEX-AGC ACC CAG TCC GCC CTG AGC A-BHQ1 }\end{array}$ & 177 & $637-794$ & $\begin{array}{c}\text { Hoffmann et al., } 2006 \\
\text { [31] }\end{array}$ \\
\hline$\beta$-Actin-Mix 2-HEX & $\begin{array}{l}\text { ACT-1005-F } \\
\text { ACT-1135-R } \\
\text { ACT-1081-HEX }\end{array}$ & $\begin{array}{c}\text { CAG CAC AAT GAA GAT CAA GAT CAT C } \\
\text { CGG ACT CAT CGT ACT CCT GCT T } \\
\text { HEX-TCG CTG TCC ACC TTC CAG CAG ATG } \\
\text { T-BHQ1 }\end{array}$ & 130 & $1005-1114$ & $\begin{array}{c}\text { Toussaint et al., } 2007 \\
\text { [32] }\end{array}$ \\
\hline
\end{tabular}

$\mathrm{PCR}=$ polymerase chain reaction, $\mathrm{CDV}=$ canine distemper virus, $\mathrm{EGFP}=$ enhanced green fluorescent Protein, $\mathrm{F}=$ forward primer, $\mathrm{R}=$ reverse primer, $\mathrm{Pb}=$ probe, $\mathrm{bp}=$ base pairs, $\mathrm{N}=$ nucleocapsid protein, $\mathrm{P}=$ phosphoprotein.

All protocols were carried out by using the AgPath-ID ${ }^{\mathrm{TM}}$ One-Step RT-PCR Reagents (Thermo FisherScientific, Waltham, MA, USA) in a $12.5 \mu \mathrm{L}$ approach. The master mix was prepared with $1.25 \mu \mathrm{L}$ RNase free water, $6.25 \mu \mathrm{L} 2 \times$ RT-PCR buffer, $0.5 \mu \mathrm{L} 25 \times$ RT-PCR Enzyme mix, $1.0 \mu \mathrm{L}$ primer-probe mix specific for the CDV detection, $1.0 \mu \mathrm{L}$ primerprobe mix for the IC system (EGFP-Mix 2-HEX or B-Actin-Mix 2-HEX) and a $2.5 \mu \mathrm{L}$ template. For generation of the CDV primer-probe-mixes, $10 \mu \mathrm{L}$ each of the forward and reverse primer $(100 \mathrm{pmol} / \mu \mathrm{L}), 2.5 \mu \mathrm{L}$ of the probe $(100 \mathrm{pmol} / \mu \mathrm{L})$ and $77.5 \mu \mathrm{L} 0.1 \times$ Tris-ethylenediaminetetraacetic acid (EDTA) $(\mathrm{pH}=8.0)$ were combined. For the IC primerprobe-mixes, $2.5 \mu \mathrm{L}$ each of the forward and reverse primer $(100 \mathrm{pmol} / \mu \mathrm{L}), 2.5 \mu \mathrm{L}$ of the probe $(100 \mathrm{pmol} / \mu \mathrm{L})$ and $92.5 \mu \mathrm{L} 0.1 \times$ Tris-EDTA $(\mathrm{pH}=8.0)$ were mixed. The temperaturetime profile was performed on the Bio-Rad CFX96 ${ }^{\mathrm{TM}}$ Real-Time PCR Detection System (BioRad Laboratories Inc., Hercules, CA, USA). A reverse transcriptase at $45{ }^{\circ} \mathrm{C}$ for $10 \mathrm{~min}$, an activation step at $95{ }^{\circ} \mathrm{C}$ for $10 \mathrm{~min}$ with a subsequent cycling process $(\mathrm{n}=45)$ of denaturation at $95^{\circ} \mathrm{C}$ in $15 \mathrm{~s}$, annealing at $56^{\circ} \mathrm{C}$ in $20 \mathrm{~s}$ and an elongation at $72{ }^{\circ} \mathrm{C}$ in $30 \mathrm{~s}$ were realized.

\subsection{Generation of a $C D V$ Standard}

For the determination of the method's analytical sensitivity, a CDV standard was produced on the basis of a whole virus standard, of which the GE copies per $\mu \mathrm{L}$ were determined by droplet digital PCR (ddPCR). For this purpose, a $\log _{10}$ dilutional series $\left(10^{-2}\right.$ to $10^{-4}$ ) of the strain "Onderstepoort" (sample ident number: BH 04/18-2) was prepared and tested in duplicate on the QX200 Droplet Digital PCR system (Bio-Rad Laboratories Inc., Hercules, CA, USA) according to the manufacturer's recommendations by using the One-Step RT-ddPCR Advanced Kit for Probes (Bio-Rad Laboratories Inc., Hercules, 
CA, USA). The master mix contained 5.0 $\mu \mathrm{L}$ RNase free water, 5.0 $\mu \mathrm{L}$ Supermix, $2.0 \mu \mathrm{L}$ Reverse Transcriptase, $1.0 \mu \mathrm{L} 300 \mathrm{mM}$ DTT, $2.0 \mu \mathrm{L}$ CDV-Mix 3 and a $5.0 \mu \mathrm{L}$ template. The results of the ddPCR were analyzed by using the software "QuantaSoft ${ }^{\mathrm{TM}}$ Analysis Pro Software" (Bio-Rad Laboratories Inc., Hercules, CA, USA). The prerequisite for the absolute quantification of the CDV standard was a clear discrimination of negative and positive droplets generated during the ddPCR run; thus, the absolute quantification of the viral standard (in GE copies per $\mu \mathrm{L}$ ) was determined.

\subsection{Analytical Sensitivity}

Three independent biological replicates were prepared, each comprising a six-fold $\log _{10}$ dilutional series $\left(10^{4}\right.$ to $\left.10^{-1}\right)$ of the whole virus standard diluted in a suspension of Madin Darby Canine Kidney (MDCK) cells. Each biological replicate was separately applied with the two selected CDV-RT-qPCRs on four different days containing three replicates per day, thus resulting in a total of 12 technical replicates per assay. The LOD was determined as the virus titer in GE copies per $\mu \mathrm{L}$ that positively detects $95 \%$ of the replicates by the selected PCR assay [33,34]. Calculations of standard deviation (SD) and coefficient of variation (CV) were performed according to Vandemeulebroucke and co-workers [35].

\subsection{Analytical Specificity}

The inclusivity (detection of samples containing related target organisms) and exclusivity (detection of only the unique target organism, but no cross-reaction to related target organisms) [36] of the CDV-specific RT-qPCR assays were tested on several available CDV strains $(n=15)$ and on a panel of morbillivirus representatives comprising peste des petits ruminants virus (PPRV, $\mathrm{n}=5$ ), phocine distemper virus (PDV, $\mathrm{n}=4)$, porpoise morbillivirus (PMV, $\mathrm{n}=1)$, dolphin morbillivirus (DMV, $\mathrm{n}=1)$ and the measles virus $(\mathrm{MV}, \mathrm{n}=2)$. A panel of paramyxovirus representatives comprising Nipah virus $(n=1)$, Hendra virus $(n=1)$, Newcastle disease virus (NDV, $n=1$ ) and bovine parainfluenza virus $3($ BPIV-3, $n=1$ ) were also included in the analytical testing.

\subsection{Diagnostic Sensitivity and Specificity}

For further validation of the methods regarding diagnostic sensitivity and specificity, a comprehensive sample panel (see Section 2.1) containing CDV-positive specimens ( $\mathrm{n}=198)$ and negative specimens $(n=180)$ was used. All samples of the validation panel were tested, with the two CDV-RT-qPCR assays currently being validated plus the CDV-RTqPCR assay of Elia and co-workers used as a reference method [27]. Diagnostic sensitivity and specificity were calculated in accordance with the two-by-two table [37,38].

\subsection{Receiver Operating Curve (ROC) Analyses}

ROC analyses were performed to determine the accuracy of the applied CDV-RT-qPCR detection systems and for a comparative evaluation between the different primer-probe assays. The test results grouped as positive and negative outcomes were contrasted, and sensitivity and 1-specificity were calculated and depicted as an ROC diagram. ROC analyses were performed according to Akobeng [39].

\subsection{Quality Assessment and Bias Statement}

All studies were carried out following the Office International des Epizooties (OIE) manual Principles and Methods of Validation of Diagnostic Assays for Infectious Diseases in an appropriate and reliable manner, as it is the industry standard for the development of veterinary diagnostic detection systems [36].

However, to standardize the parameters addressed for bias assessment, further criteria were taken into consideration $[40,41]$. These included conducting all analyses by one operator, independently interpreting the test results from an index test and reference standard and ensuring that an appropriate interval between index test and reference standards were contemplated to guarantee best bias control. 


\section{Results}

In total, $13 \mathrm{CDV}$-specific primer-probe mixes were designed and tested comparatively. A first test series carried out with a $\log _{10}$ dilutional series $\left(10^{-1}\right.$ to $\left.10^{-8}\right)$ of the CDV strain "Onderstepoort" (sample ident number: BH 04/18-2) lead to the preselection of the CDVMixes 3, 5, 7, 9 and 15 (Tables S1 and S2), considering the sensitivities and fluorescence data of all 13 CDV mixes. A diverse localization within the CDV genome was also taken into account. In terms of sensitivities, both the number of detectable dilution stages and preferably the highest relative fluorescence units (RFUs) on the last dilution stage were assessed by the CDV-Mix taken into account. For CDV-Mixes revealing similar results in both of these categories, a decision was made according to their location on the CDV genome. Further test series based on the exclusivity and inclusivity (Table S3) of the CDV-specific RT-qPCR assays displayed discrepancies for CDV-Mix 9 and 15 due to their non-specific detection pattern. According to their location on the genome, their sensitivity and their detectable RFUs, CDV-Mix 3 and CDV-Mix 7 proved to be the most appropriate CDV-RT-qPCR assays, ensuring a clear discrimination between positive and negative test results (Tables S1-S3). This was also reinforced by an in silico testing of the described oligonucleotides. The primers that were ultimately used and the TaqMan-probes for the CDV detection and the IC systems are summarized in Table 1.

Concerning the LOD, both CDV-RT-qPCR assays displayed a similar analytical sensitivity of less than $10^{1} \mathrm{GE} / \mu \mathrm{L}$ template. When using CDV-Mix 3, 31 of 36 replicates containing a template concentration of $10^{1} \mathrm{GE} / \mu \mathrm{L}$ scored positive, while only 13 replicates showed positive results by the application of CDV-Mix 7 (Table 2), which indicated a slightly better analytical performance for CDV-Mix 3. Standard deviations (SDs) of the quantification cycle (Cq)-values ranged from 0.14 to 1.11 for CDV-Mix 3 and from 0.17 to 1.15 for CDV-Mix 7. Interestingly, the highest SDs with numerical values of more than 1.0 were only achieved with replicates containing a template concentration of $10^{1} \mathrm{GE} / \mu \mathrm{L}$, regardless of the CDV-RT-qPCR assay used (Table 2).

Table 2. Evaluation of the analytical sensitivity regarding CDV-Mix 3 and CDV-Mix 7.

\begin{tabular}{|c|c|c|c|c|c|c|c|c|}
\hline \multirow[b]{2}{*}{$\begin{array}{l}\text { Concentration of } \\
\text { the Template } \\
\text { (in GE/ } / \mu \mathrm{L})\end{array}$} & \multicolumn{4}{|c|}{ CDV-Mix 3} & \multicolumn{4}{|c|}{ CDV-Mix 7} \\
\hline & $\begin{array}{l}\text { No of Positive } \\
\text { Detectable } \\
\text { Replicates }\end{array}$ & Mean Cq & SD & CV\% & $\begin{array}{l}\text { No of Positive } \\
\text { Detectable } \\
\text { Replicates }\end{array}$ & Mean Cq & SD & CV\% \\
\hline $10^{4}$ & 36 & 24.2 & 0.29 & 1.18 & 36 & 23.6 & 0.17 & 0.70 \\
\hline $10^{3}$ & 36 & 27.2 & 0.14 & 0.52 & 36 & 26.7 & 0.23 & 0.87 \\
\hline $10^{2}$ & 36 & 30.2 & 0.16 & 0.54 & 36 & 29.9 & 0.22 & 0.74 \\
\hline $10^{1}$ & 36 & 33.4 & 0.31 & 0.93 & 36 & 33.5 & 0.43 & 1.29 \\
\hline $10^{0}$ & 31 & 37.0 & 1.11 & 2.99 & 13 & 38.1 & 1.15 & 3.02 \\
\hline $10^{-1}$ & 5 & 38.7 & 0.48 & 1.23 & 1 & 38.0 & - & - \\
\hline
\end{tabular}

$\mathrm{CDV}=$ canine distemper virus, $\mathrm{GE}=$ genome equivalent, $\mathrm{Cq}=$ quantification Cycle, $\mathrm{SD}=$ standard deviation, $\mathrm{CV}=$ coefficient of variation .

In terms of analytical specificity, CDV-Mix 3 and CDV-Mix 7 were able to discriminate between the target "CDV-RNA" and the RNA of other related viruses, as 15 CDV strains were tested positive by both RT-qPCR assays. However, all specimens containing related representatives of the genus Morbillivirus (PPRV, PDV, PMV, DMV and MV) or the family Paramyxoviridae (Nipah virus, Hendra virus, NDV and BPIV-3) species were tested negative by both CDV-RT-qPCR assays.

Regarding diagnostic sensitivity and specificity, the selected CDV-RT-qPCR assays displayed comparable results when compared with the results received from the ELIA assay. All negative samples tested negative when performed with CDV-Mix 3 and CDVMix 7, indicating a diagnostic specificity of $100 \%$. For the positive sample panel, only 196 of 198 specimens scored positive in both duplex-PCR systems (Table S1). The diagnostic sensitivity for the new CDV-RT-qPCR assays was calculated as $98.9 \%$. Within all applied 
PCR runs, functionality of the integrated heterologous and endogenous ICs was verified and stated.

The diagnostic accuracy of the CDV-RT-qPCR assays was determined by calculating and visualizing the ROCs (Figure 1). Based on the ROC, the area under the curve (AUC) was calculated. The CDV-Mix 3 revealed an AUC of 0.960 (95\% Confidence Interval (CI): 0.903 to 1.000). The AUC of CDV-Mix 7 was 0.970 (95\% CI: 0.926 to 1.000), and that of the ELIA-Mix was 0.966 (95\% CI: 0.913 to 1.000). According to these results, the three CDV-RT-qPCR assays had very high diagnostic accuracies.
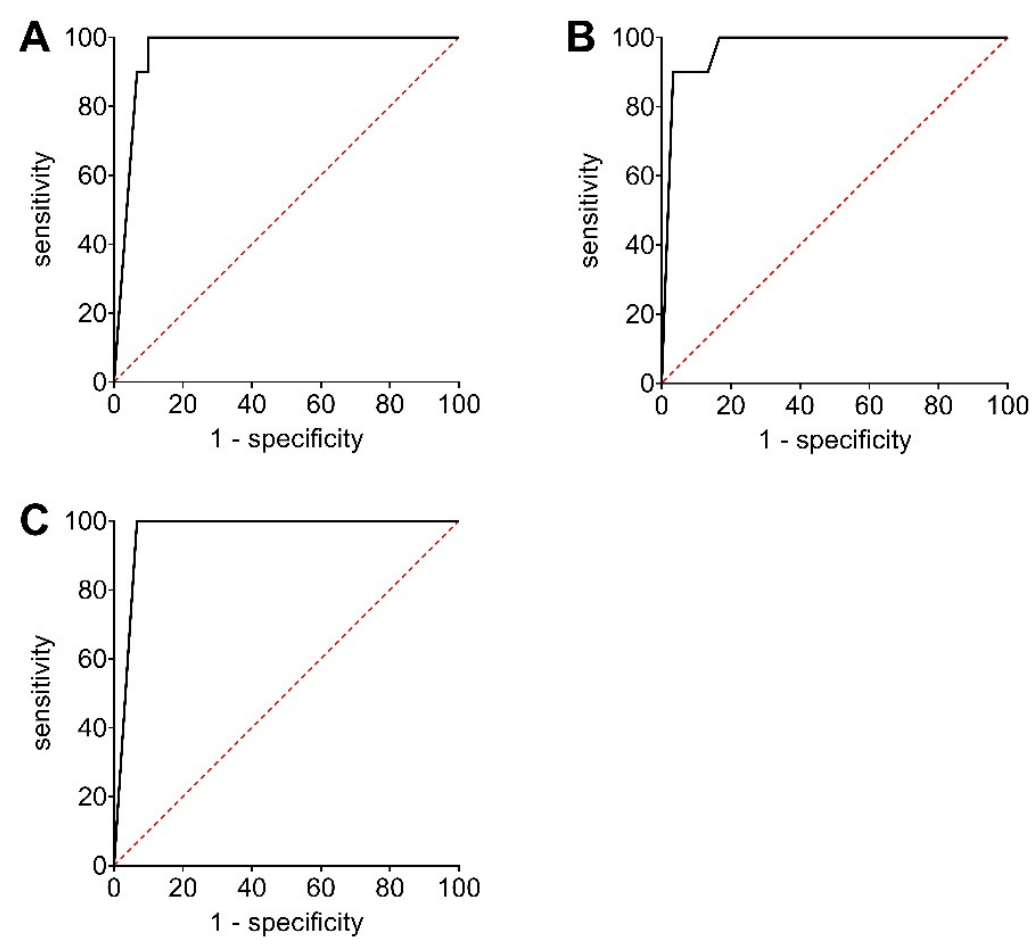

Figure 1. Receiver operating curve (ROC) analyses illustrating the relation of sensitivity and 1specificity of CDV-Mix 3 (A), CDV-Mix 7 (B) and ELIA Mix (C).

\section{Discussion}

Global considerations about increasing case reports of CDV reinforced concerns about suspected new virus variants, which also indicate a challenge for established diagnostic methods for the molecular detection of CDV. An inter-laboratory proficiency test in Germany and a sequence alignment with the latest available CDV sequences on the NCBI database and sequences of established CDV-specific primer-probe mixes revealed the diagnostic incompatibilities of currently used CDV-RT-qPCR assays. Moreover, in this study, a small panel of PDV-positive samples $(n=4)$ were tested by the comparative application of CDV-Mix 3, CDV-Mix 7 and the ELIA-Mix. Here, the ELIA-Mix displayed obvious drawbacks regarding its analytical exclusivity as two of four PDV-positive samples were recognized as positive. In the test series, which was carried out for validation purposes of the new CDV-RT-qPCR, the ELIA-Mix revealed major discrepancies in the sensitive detection of a few isolates concerning the Cq values (Table S4). Regarding the publication and validation of the ELIA-Mix, a reliable and transparent IC system was also unable to be established. These major findings confirmed standout deficiencies concerning the CDV-RT-qPCR currently in use and support the necessity of a revision of CDV-specific RT-qPCRs. In order to advance safe and reliable CDV diagnosis in domestic and wild animals, an extended molecular diagnostic approach based on RT-qPCR technology with double-check strategy was developed.

A decisively modified Scagliarini assay [28], which were designated as CDV-Mix 3 and located on a conserved region of the $P$ gene, were combined with a newly designed 
RT-qPCR assay referred to as CDV-Mix 7 and targeting the $P$ gene, These two independent CDV-RT-qPCR assays were applied for the double-check PCR system. The new PCR assays were proven to be highly sensitive and specific RT-qPCR systems that were adapted to the latest available CDV sequence information and, thus, met the requirements of improved CDV diagnostic methods. The analytical sensitivity of both new CDV-RT-qPCR assays was similar, as a copy number of less than $10^{1} \mathrm{GE} / \mu \mathrm{L}$ was set as the LOD for both assays. When considering the LODs of the original Scagliarini assay $\left(10^{1} \mathrm{GE} / \mu \mathrm{L}\right)$ and the ELIA assay $\left(10^{2} \mathrm{GE} / \mu \mathrm{L}\right)$, the newly validated RT-qPCR assays proved to be highly sensitive in terms of analytical performance. In addition, the discrimination of non-CDV species was analyzed in an initial test series, as deficiencies were stated for established CDV-RT-qPCRs. CDV-Mix 3 and CDV-Mix 7 consistently detected positive samples of virus species belonging to the genus Morbillivirus and/or the family Paramyxoviridae and those not CDV-positive were denoted as negative; thus, the new CDV-RT-qPCR assays were demonstrated to be superior to the ELIA-Mix in terms of analytical specificity. Comprehensive validation test series were performed on a panel of 378 samples and revealed a diagnostic sensitivity of $98.9 \%$ and a diagnostic specificity of $100 \%$ for both assays, including the reliable testing of samples belonging to different host species (foxes, racoons, martens, dogs, racoon dogs, wolves, badgers, minks, polar fox, otter and red panda), a diverse organ panel (brain, lung, liver, lymph node, kidney and spleen) and geographically widely distributed sampling sites (Germany, Austria, Italy, Spain, Romania, Ukraine and Africa). The primer and probes of both new RT-qPCR systems were located on the $P$ gene, whereas the reference method by ELIA and co-workers was located on the $N$ gene, which can be a strong explanation for the similar analytical and diagnostic validation outcome of CDV-Mix 3 and CDV-Mix 7.

Additionally, both CDV-RT-qPCR assays can be mutually combined with a heterologous (EGFP-Mix 2-HEX) and an endogenous IC (B-Actin-Mix 2-HEX) as it is a verification tool for an efficient RNA extraction, a functioning amplification during the PCR run and the presence of inhibitors [31]. ICs are considered a quality criterion in molecular diagnostic methods, especially when using biological sample material of decomposed quality [29,32].

The parallel application of at least two RT-qPCR assays ensures a safe and reliable CDV diagnosis because two independent results per sample are available within one run, while the master mix of each CDV-RT-qPCR assay was reduced to $12.5 \mu \mathrm{L}$ and the assays are equipped with ICs for quality assurance. The new molecular detection system for CDV was validated with a comprehensive sample panel, indicating a reliable performance on different sample matrices (organs and host animals) in addition to being based on samples of a geographically widespread distribution within Europe. Most of the accessible samples applied for the validation of the new CDV-RT-qPCR assays were collected in European countries and therefore belonged to the European clusters of the CDV lineages. The results are lacking with regard to addressing information about the applicability and reliability of the new molecular detection system in terms of furthering CDV clusters. Future applications of the validated CDV-RT-qPCR assays will underpin their diagnostic capacity with regard to the evolved genetic dynamic on the sequence level recognized in recent years. Furthermore, the diagnostic performance of the CDV-RT-qPCR assays for CDV lineages that have yet to be tested should be addressed.

Supplementary Materials: The following are available online at https:/ / www.mdpi.com/article / 10.3390/v13081632/s1, Table S1: Comparative test series on initial 13 CDV RT-qPCR assays carried out with AgPath-ID ${ }^{\mathrm{TM}}$ One-Step RT-PCR Reagents and based on a $\log 10$ dilutional series $\left(10^{-1}\right.$ to $10^{-8}$ ) of the CDV strain "Onderstepoort" (sample ID: BH 04/18-2) by contrast with the ELIA-Mix: the locations within the genome are shown for each single CDV RT-qPCR assay, and the results are shown in Cq values; Table S2: Comparative test series on initial 13 CDV RT-qPCR assays carried out on the Bio-Rad CFX96 ${ }^{\mathrm{TM}}$ Real-Time PCR Detection System and based on a log10 dilutional series $\left(10^{-1}\right.$ to $10^{-8}$ ) of the CDV strain "Onderstepoort" (sample ID: BH 04/18-2) by contrast with the ELIA-Mix: the results are shown in RFU values; Table S3: Test series on the exclusivity and inclusivity of five preselected CDV RT-qPCR assays using different isolates of the four lineages of PPRV (L1 to L4), MVand Cetacean morbilliviruses (CeMV), the test series carried out with isolates of representatives of 
paramyxovirues (NDV, Nipah virus, Hendra virus and BPIV-3) were negative for all five CDV-mixes (not shown here); Table S4: Validation data of positive samples carried out by the one-step RT-qPCR for CDV detection.

Author Contributions: Conceptualization, S.B. and B.H.; methodology, B.H. and S.H.; validation, S.H. and B.H.; formal analysis, S.H. and B.H.; investigation, S.H.; resources, S.B., B.H. and M.B.; data curation, S.H. and B.H.; writing-original draft preparation, S.H.; writing-review and editing, M.B., B.H.; supervision, B.H.; project administration, B.H. All authors have read and agreed to the published version of the manuscript.

Funding: This research received no external funding.

Institutional Review Board Statement: Not applicable.

Informed Consent Statement: Not applicable.

Data Availability Statement: Data are contained within the article and the supplementary materials.

Acknowledgments: We thank Christian Grund for the supply of viral RNA of several NDV isolates as well as Sven Reiche for the kind provision of the virus isolates containing CDV, NDV and PMV. Furthermore, our thanks go to Silke Hechinger, Susanne Rickling, Adi Steinrigl and Ludwig Haas for the kind provision of sample material.

Conflicts of Interest: The authors declare that they have no conflict of interest.

\section{References}

1. Beineke, A.; Baumgartner, W.; Wohlsein, P. Cross-species transmission of canine distemper virus-an update. One Health 2015, 1, 49-59. [CrossRef]

2. Kapil, S.; Yeary, T.J. Canine distemper spillover in domestic dogs from urban wildlife. Vet. Clin. N. Am. Small Anim. Pract. 2011, 41,1069-1086. [CrossRef]

3. Martinez-Gutierrez, M.; Ruiz-Saenz, J. Diversity of susceptible hosts in canine distemper virus infection: A systematic review and data synthesis. BMC Vet. Res. 2016, 12, 78. [CrossRef] [PubMed]

4. $\quad$ Barthold, S.W.; Bowen, R.A.; Hedrick, R.P.; Knowles, D.P.; Lairmore, M.D.; Parrish, C.R.; Saif, L.J.; Swayne, D.E. Fenner's Veterinary Virology, 4th ed.; MacLachlan, N.J., Dubovi, E.J., Eds.; Elsevier Inc.: Amsterdam, The Netherlands, 2011.

5. ICTV. ICTV Taxonomy History: Canine Morbillivirus. Available online: https://talk.ictvonline.org//taxonomy/p/taxonomyhistory?taxnode_id=201851613 (accessed on 3 January 2020).

6. Rendon-Marin, S.; da Fontoura Budaszewski, R.; Canal, C.W.; Ruiz-Saenz, J. Tropism and molecular pathogenesis of canine distemper virus. Virol. J. 2019, 16, 30. [CrossRef] [PubMed]

7. Duque-Valencia, J.; Sarute, N.; Olarte-Castillo, X.A.; Ruiz-Saenz, J. Evolution and Interspecies Transmission of Canine Distemper Virus-An Outlook of the Diverse Evolutionary Landscapes of a Multi-Host Virus. Viruses 2019, 11, 582. [CrossRef]

8. Ricci, I.; Cersini, A.; Manna, G.; Marcario, G.A.; Conti, R.; Brocherel, G.; Grifoni, G.; Eleni, C.; Scicluna, M.T. A Canine Distemper Virus Retrospective Study Conducted from 2011 to 2019 in Central Italy (Latium and Tuscany Regions). Viruses 2021, 13, 272. [CrossRef] [PubMed]

9. Riley, M.C.; Wilkes, R.P. Sequencing of emerging canine distemper virus strain reveals new distinct genetic lineage in the United States associated with disease in wildlife and domestic canine populations. Virol. J. 2015, 12, 219. [CrossRef] [PubMed]

10. Anis, E.; Holford, A.L.; Galyon, G.D.; Wilkes, R.P. Antigenic analysis of genetic variants of Canine distemper virus. Vet. Microbiol. 2018, 219, 154-160. [CrossRef] [PubMed]

11. Loots, A.K.; Mitchell, E.; Dalton, D.L.; Kotze, A.; Venter, E.H. Advances in canine distemper virus pathogenesis research: A wildlife perspective. J. Gen. Virol. 2017, 98, 311-321. [CrossRef]

12. Yon, L.; Duff, J.P.; Agren, E.O.; Erdelyi, K.; Ferroglio, E.; Godfroid, J.; Hars, J.; Hestvik, G.; Horton, D.; Kuiken, T.; et al. Recent Changes in Infectious Diseases in European Wildlife. J. Wildl. Dis. 2019, 55, 3-43. [CrossRef]

13. Di Blasio, A.; Irico, L.; Caruso, C.; Miceli, I.; Robetto, S.; Peletto, S.; Varello, K.; Giorda, F.; Mignone, W.; Rubinetti, F.; et al. Canine Distemper Virus as an Emerging Multihost Pathogen in Wild Carnivores in Northwest Italy. J. Wildl. Dis. 2019, 55, 844-856. [CrossRef]

14. Garigliany, M.; Sarlet, M.; Franssen, M.; Desmecht, D.; Volpe, R.; Lesenfants, C.; Paternostre, J.; Linden, A. Re-emergence of canine distemper in wildlife in Belgium. Vet. Rec. 2018, 182, 439. [CrossRef] [PubMed]

15. Gregers-Jensen, L.; Agger, J.F.; Hammer, A.S.; Andresen, L.; Chriel, M.; Hagberg, E.; Jensen, M.K.; Hansen, M.S.; Hjulsager, C.K.; Struve, T. Associations between biosecurity and outbreaks of canine distemper on Danish mink farms in 2012-2013. Acta Vet. Scand. 2015, 57, 66. [CrossRef] [PubMed]

16. Molenaar, R.J.; Buter, R. Outbreaks of canine distemper in Dutch and Belgian mink farms. Vet. Q 2018, 38, 112-117. [CrossRef]

17. Monne, I.; Fusaro, A.; Valastro, V.; Citterio, C.; Dalla Pozza, M.; Obber, F.; Trevisiol, K.; Cova, M.; De Benedictis, P.; Bregoli, M.; et al. A distinct CDV genotype causing a major epidemic in Alpine wildlife. Vet. Microbiol. 2011, 150, 63-69. [CrossRef] [PubMed] 
18. Renteria-Solis, Z.; Forster, C.; Aue, A.; Wittstatt, U.; Wibbelt, G.; Konig, M. Canine distemper outbreak in raccoons suggests pathogen interspecies transmission amongst alien and native carnivores in urban areas from Germany. Vet. Microbiol. 2014, 174, 50-59. [CrossRef] [PubMed]

19. Sekulin, K.; Hafner-Marx, A.; Kolodziejek, J.; Janik, D.; Schmidt, P.; Nowotny, N. Emergence of canine distemper in Bavarian wildlife associated with a specific amino acid exchange in the haemagglutinin protein. Vet. J. 2011, 187, 399-401. [CrossRef] [PubMed]

20. Ek-Kommonen, C.; Sihvonen, L.; Pekkanen, K.; Rikula, U.; Nuotio, L. Outbreak off canine distemper in vaccinated dogs in Finland. Vet. Rec. 1997, 141, 380-383. [CrossRef] [PubMed]

21. Rikula, U.; Nuotio, L.; Sihvonen, L. Vaccine coverage, herd immunity and occurrence of canine distemper from 1990-1996 in Finland. Vaccine 2007, 25, 7994-7998. [CrossRef]

22. Bhatt, M.; Rajak, K.K.; Chakravarti, S.; Yadav, A.K.; Kumar, A.; Gupta, V.; Chander, V.; Mathesh, K.; Chandramohan, S.; Sharma, A.K.; et al. Phylogenetic analysis of haemagglutinin gene deciphering a new genetically distinct lineage of canine distemper virus circulating among domestic dogs in India. Transbound Emerg. Dis. 2019, 66, 1252-1267. [CrossRef]

23. Vergara-Wilson, V.; Hidalgo-Hermoso, E.; Sanchez, C.R.; Abarca, M.J.; Navarro, C.; Celis-Diez, S.; Soto-Guerrero, P.; Diaz-Ayala, N.; Zordan, M.; Cifuentes-Ramos, F.; et al. Canine Distemper Outbreak by Natural Infection in a Group of Vaccinated Maned Wolves in Captivity. Pathogens 2021, 10, 51. [CrossRef]

24. Almuna, R.; Lopez-Perez, A.M.; Sarmiento, R.E.; Suzan, G. Drivers of canine distemper virus exposure in dogs at a wildlife interface in Janos, Mexico. Vet. Rec. Open 2021, 8, e7. [CrossRef]

25. Viana, M.; Cleaveland, S.; Matthiopoulos, J.; Halliday, J.; Packer, C.; Craft, M.E.; Hampson, K.; Czupryna, A.; Dobson, A.P.; Dubovi, E.J.; et al. Dynamics of a morbillivirus at the domestic-wildlife interface: Canine distemper virus in domestic dogs and lions. Proc. Natl. Acad. Sci. USA 2015, 112, 1464-1469. [CrossRef] [PubMed]

26. Batista Linhares, M.; Whiteley, H.E.; Samuelson, J.P.; Hsiao, S.H.; Stern, A.W.; Sprandel, I.T.; Roady, P.J.; Coleman, D.A.; Rizzo, R.; Froderman, S.F.; et al. Sylvatic Canine Morbillivirus in Captive Panthera Highlights Viral Promiscuity and the Need for Better Prevention Strategies. Pathogens 2021, 10, 544. [CrossRef] [PubMed]

27. Elia, G.; Decaro, N.; Martella, V.; Cirone, F.; Lucente, M.S.; Lorusso, E.; Di Trani, L.; Buonavoglia, C. Detection of canine distemper virus in dogs by real-time RT-PCR. J. Virol. Methods 2006, 136, 171-176. [CrossRef] [PubMed]

28. Scagliarini, A.; Dal Pozzo, F.; Gallina, L.; Vaccari, F.; Morganti, L. TaqMan based real time PCR for the quantification of canine distemper virus. Vet. Res. Commun. 2007, 31 (Suppl. 1), 261-263. [CrossRef] [PubMed]

29. Wernike, K.; Beer, M.; Freuling, C.M.; Klupp, B.; Mettenleiter, T.C.; Muller, T.; Hoffmann, B. Molecular double-check strategy for the identification and characterization of Suid herpesvirus 1. J. Virol. Methods 2014, 209, 110-115. [CrossRef]

30. Fischer, M.; Freuling, C.M.; Muller, T.; Wegelt, A.; Kooi, E.A.; Rasmussen, T.B.; Voller, K.; Marston, D.A.; Fooks, A.R.; Beer, M.; et al. Molecular double-check strategy for the identification and characterization of European Lyssaviruses. J. Virol. Methods 2014, 203, 23-32. [CrossRef]

31. Hoffmann, B.; Depner, K.; Schirrmeier, H.; Beer, M. A universal heterologous internal control system for duplex real-time RT-PCR assays used in a detection system for pestiviruses. J. Virol. Methods 2006, 136, 200-209. [CrossRef]

32. Toussaint, J.F.; Sailleau, C.; Breard, E.; Zientara, S.; De Clercq, K. Bluetongue virus detection by two real-time RT-qPCRs targeting two different genomic segments. J. Virol. Methods 2007, 140, 115-123. [CrossRef]

33. Burns, M.; Valdivia, H. Modelling the limit of detection in real-time quantitative PCR. Eur. Food Res. Technol. 2008, 226, 1513-1524. [CrossRef]

34. Forootan, A.; Sjoback, R.; Bjorkman, J.; Sjogreen, B.; Linz, L.; Kubista, M. Methods to determine limit of detection and limit of quantification in quantitative real-time PCR (qPCR). Biomol. Detect. Quantif. 2017, 12, 1-6. [CrossRef] [PubMed]

35. Vandemeulebroucke, E.; De Clercq, K.; Van der Stede, Y.; Vandenbussche, F. A proposed validation method for automated nucleic acid extraction and RT-qPCR analysis: An example using Bluetongue virus. J. Virol. Methods 2010, 165, 76-82. [CrossRef] [PubMed]

36. OIE. Chapter 1.1.5. Principles and methods of validation of diagnostic assays for infectious diseases. In OIE Terrestrial Manual 2013; OIE: Paris, France, 2019; Volume 2013, pp. 1-16.

37. Parikh, R.; Mathai, A.; Parikh, S.; Chandra Sekhar, G.; Thomas, R. Understanding and using sensitivity, specificity and predictive values. Indian J. Ophthalmol. 2008, 56, 45-50. [CrossRef] [PubMed]

38. Akobeng, A.K. Understanding diagnostic tests 1: Sensitivity, specificity and predictive values. Acta Paediatr. 2007, 96, 338-341. [CrossRef] [PubMed]

39. Akobeng, A.K. Understanding diagnostic tests 3: Receiver operating characteristic curves. Acta Paediatr. 2007, 96, 644-647. [CrossRef]

40. Whiting, P.; Rutjes, A.W.; Reitsma, J.B.; Bossuyt, P.M.; Kleijnen, J. The development of QUADAS: A tool for the quality assessment of studies of diagnostic accuracy included in systematic reviews. BMC Med. Res. Methodol. 2003, 3, 25. [CrossRef]

41. Whiting, P.F.; Weswood, M.E.; Rutjes, A.W.; Reitsma, J.B.; Bossuyt, P.N.; Kleijnen, J. Evaluation of QUADAS, a tool for the quality assessment of diagnostic accuracy studies. BMC Med. Res. Methodol. 2006, 6, 9. [CrossRef] 